Research Article

\title{
Shielding Design and Dose Evaluation for HTR-PM Fuel Transport Pipelines by QAD-CGA Program
}

\author{
Sheng Fang $\left(\mathbb{D},{ }^{1}\right.$ Jianzhu Cao, ${ }^{1}$ Wenqian Li $\left(\mathbb{D},{ }^{1}\right.$ Chen Luo, ${ }^{2}$ Feng Yao, ${ }^{1}$ Xiaofan Li, ${ }^{3}$ and Kai Li ${ }^{3}$ \\ ${ }^{1}$ Institute of Nuclear and New Energy Technology, Collaborative Innovation Centre of Advanced Nuclear Energy Technology, \\ Key Laboratory of Advanced Reactor Engineering and Safety, Ministry of Education, Tsinghua University, Beijing, China \\ ${ }^{2}$ Beijing Institute of Metrology, Beijing, China \\ ${ }^{3}$ CNNC Everclean Environmental Engineering Co., Ltd, Beijing 100037, China
}

Correspondence should be addressed to Wenqian Li; mili@mail.tsinghua.edu.cn

Received 12 October 2020; Revised 7 April 2021; Accepted 26 April 2021; Published 4 May 2021

Academic Editor: Keith E. Holbert

Copyright (C) 2021 Sheng Fang et al. This is an open access article distributed under the Creative Commons Attribution License, which permits unrestricted use, distribution, and reproduction in any medium, provided the original work is properly cited.

\begin{abstract}
The spherical fuel elements are adopted in the high-temperature gas-cooled reactor pebble-module (HTR-PM). The fuel elements will be discharged continuously from the reactor core and transported into the fuel transport pipelines during the reactor operation, leading to spatially varying dose outside the pipeline. In this case, the dose evaluation faces two major challenges, including dynamic source terms and pipelines with varying lengths and shapes. This study tries to handle these challenges for HTR-PM through comprehensive calculations using the QAD-CGA program and to design the corresponding shielding of the pipeline. During the calculation, it is assumed that a spherical fuel element stays in different positions of the pipelines in turn, and the corresponding dose contributions were calculated. By integrating the dose contributions at different positions, the dose at the points of interest can be obtained. The total dose is further determined according to the assumed fuel elements transport speed of $5 \mathrm{~m} / \mathrm{s}$ and total 6000 fuel elements transportation per day. Two types of fuel transport pipelines and two source terms were considered, i.e., the spent fuel element transport pipelines with corresponding spent fuel source term and the different burn-up fuel element transport pipelines with the average burn-up fuel source term. Doses at different points of interest were calculated with no shielding scenario and with lead shielding of different thicknesses scenario. To evaluate the shielding effect, the dose limit of the orange radiation zone of HTR-PM and the radiation damage thresholds from NCRP report No.51 were both adopted. The calculated results show that, for pipelines that transport the spent fuel, a $4 \mathrm{~cm}$ lead shielding will be enough. And for pipelines that transport fuel elements with different burn-up, a $5 \mathrm{~cm}$ lead shielding will be added. The method and results can provide valuable reference for other work of HTR-PM.
\end{abstract}

\section{Introduction}

The high-temperature gas-cooled reactor pebble-module (HTR-PM) is undergoing commissioning in Shandong Province of China. It has many characteristics different from the traditional pressurized water reactors [1-5]. The spherical graphite coated components are adopted in HTRPM reactor as fuel elements. Each spherical fuel element is $60 \mathrm{~mm}$ in diameter and coating about $8000 \mathrm{UO}_{2}$ kernels in it. During the operation of the reactor, the spherical fuel elements will be removed and reloaded into the core periodically through the fuel transport pipelines [6]. Without enough shielding, the dose rate outside the pipelines will be too high, since the irradiated spherical fuel elements are severely activated. For practical engineering design, two types of pipelines are worth attention. One is for the spent fuel elements transport, and the other is for the transport of fuel elements with different burn-up. The transport of both spherical fuel elements involves dynamic source terms. In addition, the length of the pipelines varies from place to place, leading to different dose in each case.

For the shielding calculation, the Monte Carlo simulation method and the empirical formula approximation calculation method are commonly employed. The Monte Carlo method can deal with complex geometric structures, material composition, and source terms, by simulating the real particle 
transport process, such as scattering, transmission, and absorption. Widely used software based on the Monte Carlo method includes MCNP [7-9], FLUKA (http://www.fluka.org/fluka.php; [10], GEANT4 [11, 12], and so on. However, the Monte Carlo method usually requires a longer calculation time. The QAD-CGA program, which is based on the pointkernel integration technique, is especially suitable for dealing with shielding design problems under simple geometric structures. The scattering of particles is approximated by the buildup factor $[13,14]$. After comparison and verification, under the simple geometric model, the QAD-GCA program has the advantages of fast calculation speed and accurate results [15-19]. The dose evaluation along the pipelines involves only a simple geometry, but requires repetitive calculation with varying source terms. These features make the QAD-CGA program a good candidate for the dose calculation.

For the above reason, the QAD-CGA is used to calculate the dose caused by a moving fuel element in this study. The dose rates by a fuel element at different positions are calculated at the points of interest. Based on the speed of the fuel element, the total dose at the point of interest is calculated by integrating the dose rates with the duration of the fuel element at each position. This method is applied to the calculation of the point-by-point dose rate for a single spent fuel element, the average hourly dose rate from 6000 elements per day, and the cumulative dose of 40 years from 6000 elements per day for different cases. The results are compared with the dose limit of the orange radiation zone of HTR-PM and the thresholds of radiation tolerance of different materials from NCRP report No. 51.

\section{Method}

2.1. Source Terms. The spherical fuel elements will pass through the fuel transport pipelines at an average speed of $5 \mathrm{~m} / \mathrm{s}$. Two types of source terms need to be considered: (1) the spent fuel and (2) the average burn-up fuel, which is for the fuel elements transport with different burn-up. Normally, there will be 6000 elements passing through the pipelines per day.

The source term for the average burn-up fuel is calculated under the assumption that the proportion of the fuel elements

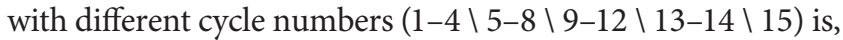
respectively, $1.2 / 15,1.1 / 15,1.0 / 15,0.9 / 15$, and 0 .

The KORIGEN code was adopted to calculate the gamma source terms. KORIGEN is a KARLSRUHE version of the ORIGEN code [20] developed by the Oak Ridge National Laboratory, which contains an updated nuclide cross section data library for high-temperature gas-cooled reactors. KORIGEN calculates the radionuclide inventory at the equilibrium of the reactor, by solving deterministic differential equations. It can calculate irradiation in both thermal and fast-neutron spectra [21-24].

From the KORIGEN calculation, there will be more than 60 radionuclides in a spent fuel element [25]. Figure 1 shows the gamma-ray intensity of the two source terms, which were derived from the radionuclide inventory. For the spent fuel

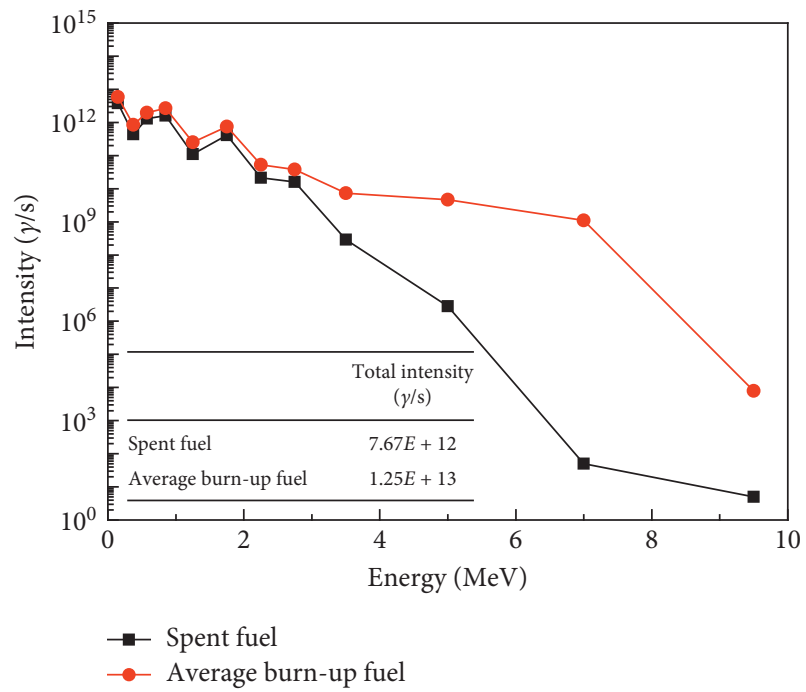

FIGURE 1: The source terms for the spent fuel and the average burnup fuel.

source term, the total gamma intensity is $7.67 \times 10^{12} \gamma / \mathrm{s}$. For the average burn-up fuel source term, the total gamma intensity is $1.25 \times 10^{13} \mathrm{\gamma} / \mathrm{s}$.

2.2. Geometry Model. The outer diameter of the fuel transport pipelines is $69 \mathrm{~mm}$ with a thickness of $2 \mathrm{~mm}$ as shown in Figure 2. The pipeline is made of stainless steel with density of $7.8 \mathrm{~g} / \mathrm{cm}^{3}$. Its main component is iron and also contains impurities, such as carbon, silicon, manganese, nickel, chromium, and titanium. In the calculation, the composition of the pipeline was simplified to iron. The points of interest were all chosen in the middle line of the pipeline. The distance between one point of interest and the outside of the pipeline is defined as Dpi.

For pipelines that transport the spent fuel, two scenarios were considered: with no shielding and with a $4 \mathrm{~cm}$ lead shielding. For pipelines that transport fuel elements with different burn-up, three scenarios were considered: with no shielding, with a $4.5 \mathrm{~cm}$ lead shielding, and with a $5 \mathrm{~cm}$ lead shielding.

When the spherical fuel element moves from the left side to the right side of the pipeline, its dose contribution to the points of interest at different positions of the pipeline may vary greatly. In this work, the following method was adopted to calculate the total dose at one point of interest produced by a spherical fuel element passing through the pipeline one time.

Taking the $5 \mathrm{~m}$-length pipeline as an example, its left half can be divided into 13 segments, as shown in Figure 2, where $\mathrm{AB}, \mathrm{BC}, \mathrm{CD}$ to LM are all $20 \mathrm{~cm}$ length (12 segments in total), and the length of the $\mathrm{MN}$ is $10 \mathrm{~cm}$.

Define the dose from a spherical fuel element to one point of interest during its movement in the $A B$ segment as $\mathrm{D}_{\mathrm{AB}} \cdot \mathrm{D}_{\mathrm{AB}}$ can be conservatively calculated by

$$
D_{A B}=d_{B} \times t_{B}
$$




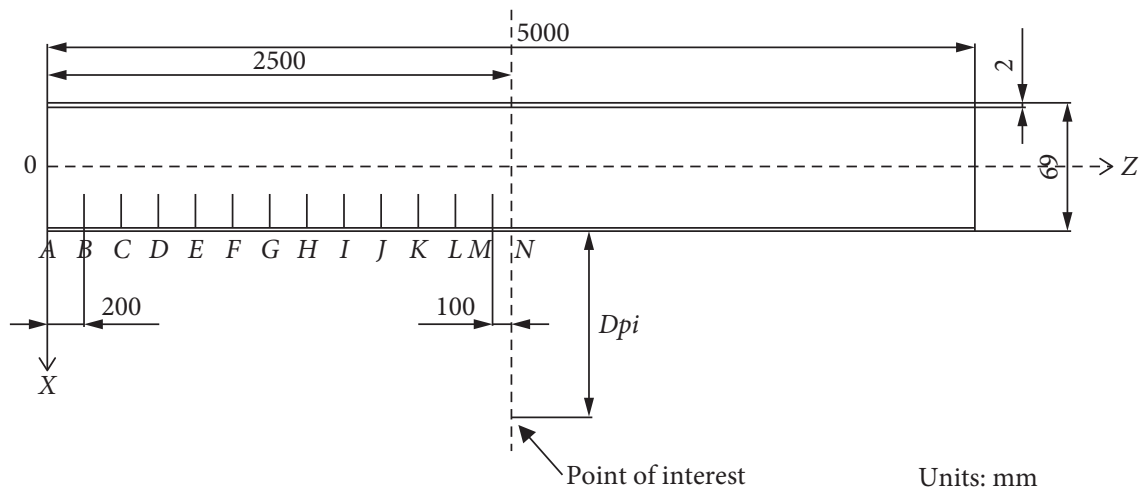

FIgURe 2: The geometry structure in the QAD-CGA calculation.

where $d_{B}$ is the dose rate of the spherical fuel element at point $B$ and $t_{B}$ is the time required for the fuel element to pass through the $\mathrm{AB}$ segment.

For the other segments, the calculation method is similar. Since the points of interest are located in the middle of the pipeline, due to the symmetrical relationship, the spherical fuel element gives the same dose to one point of interest when it moves in the left half and right half sections. Then, the dose from a spherical fuel element to the point of interest during its movement along the whole pipeline $(D)$ can be calculated by

$$
D=2 \times \sum\left(D_{A B}, D_{B C}, \ldots, D_{L M}\right)+D_{M N} .
$$

2.3. Dose Limit. We focus on $\dot{D}$ and $D_{40 y}$, which are defined as follows: $\dot{D}$ is the average hourly dose rate from 6000 elements per day, $\mathrm{mGy} / \mathrm{h}$, which can be calculated by equation (3); $D_{40 y}$ is the cumulative dose of 40 years from 6000 elements per day, Gy, which can be calculated by equation (4).

$$
\begin{aligned}
\dot{D} & =D \times\left(\frac{6000}{24}\right), \\
D_{40 y} & =\dot{D} \times 40 \times 365.25 \times \frac{24}{1000} .
\end{aligned}
$$

For $D_{p i}=30 \mathrm{~cm}$, the dose limit of $\dot{D}$ should be $3 \mathrm{mGy} / \mathrm{h}$, which is the upper limit value of the orange radiation zone of HTR-PM.

For $D_{40 \mathrm{y}}$, it is mainly used to evaluate the material radiation damage. Two concerned radiation damage thresholds are listed in Table 1 (NCRP report No. 51) [25].

\section{Results and Discussion}

3.1. For Pipelines That Transport the Spent Fuel. For pipelines that transport the spent fuel, two scenarios were considered: pipelines with no shielding and with a $4 \mathrm{~cm}$ lead shielding.

Firstly, for each case, the point-by-point dose rate by one spent fuel element should be calculated. Figure 3 shows one of the point-by-point dose rates calculated results. It is relative to a point of interest of $\mathrm{Dpi}=30 \mathrm{~cm}$ and for a $5 \mathrm{~m}$ pipeline with no shielding case.
Table 1: Two concerned radiation damage thresholds.

\begin{tabular}{lc}
\hline Item & Threshold (Gy) \\
\hline Plastics losing tensile strength & $1 \times 10^{4}-1 \times 10^{7}$ \\
Natural rubber losing elasticity & $5 \times 10^{4}-3 \times 10^{5}$ \\
\hline
\end{tabular}

From Figure 3, it can be seen, at point B, the dose rate is $239 \mathrm{mGy} / \mathrm{h}$, while at point $\mathrm{N}$ the dose rate increases to $2.09 \times 10^{4} \mathrm{mGy} / \mathrm{h}$, which is 2 orders of magnitude higher than point B's dose rate. So, it can be drawn that the dose of points of interest is mainly affected by the segments near the middle of the pipeline.

Then, based on the point-by-point dose rate results, the $\dot{D}$ and $D_{40 \text { y }}$ results of different Dpi and different pipeline lengths can be calculated by equations (3) and (4).

Figure 4 shows the average hourly dose rate $\dot{D}$ at different $D p i$ positions for a $5 \mathrm{~m}$ pipeline, from which it can be seen, for the pipeline with no shielding case, at $D p i=30 \mathrm{~cm}$ 's position, $\dot{\mathrm{D}}=318 \mathrm{mGy} / \mathrm{h}$; and at $D p i=500 \mathrm{~cm}$ 's position, $\dot{\mathrm{D}}=5.99 \mathrm{mGy} / \mathrm{h}$, which decreased by two orders of magnitude. For the pipeline with a $4 \mathrm{~cm}$ lead shielding case, the $\dot{D}$ at $D p i=30 \mathrm{~cm}$ and $500 \mathrm{~cm}$ are $2.86 \mathrm{mGy} / \mathrm{h}$ and $9.74 \times 10^{-2} \mathrm{mGy} / \mathrm{h}$, respectively. It can be drawn that a $4 \mathrm{~cm}$ lead shielding can reduce the dose rates at points of interest with the same Dpi by nearly two orders of magnitude.

Figure 5 shows the calculated $D_{40 y}$ results at different Dpi positions for a $5 \mathrm{~m}$ pipeline, from which it can be seen, for the pipeline with no shielding case, at $D p i=30 \mathrm{~cm}$ 's position, $D_{40 \mathrm{y}}=1.11 \times 10^{5} \mathrm{~Gy} ;$ and at $D p i=500 \mathrm{~cm}$ 's position, $D_{40 \mathrm{y}}=2.1 \times 10^{3} \mathrm{~Gy}$, which also decreased by two orders of magnitude. For the pipeline with a $4 \mathrm{~cm}$ lead shielding, the $D_{40 y}$ at $D p i=30 \mathrm{~cm}$ and $500 \mathrm{~cm}$ are $1000 \mathrm{~Gy}$ and $34.2 \mathrm{~Gy}$, respectively. Similarly, as $\dot{D}$, a $4 \mathrm{~cm}$ lead shielding can reduce $D_{40 y}$ at points of interest with the same $D p i$ by nearly two orders of magnitude.

Table 2 lists the $\dot{D}$ and $D_{40 \mathrm{y}}$ values at $D p i=30 \mathrm{~cm}$ 's position for pipelines of 1-5 $\mathrm{m}$ length. The calculation results show that when the pipeline lengths are changed from $1 \mathrm{~m}$ to $5 \mathrm{~m}$, the $\dot{D}$ at $D p i=30 \mathrm{~cm}$ increases from $227 \mathrm{mGy} / \mathrm{h}$ to $318 \mathrm{mGy} / \mathrm{h}$, while with a $4 \mathrm{~cm}$ lead shielding, the $\dot{D}$ at $D p i=30 \mathrm{~cm}$ increases from $2.72 \mathrm{mGy} / \mathrm{h}$ to $2.86 \mathrm{mGy} / \mathrm{h}$ when the length of the pipeline changes from $1 \mathrm{~m}$ to $3 \mathrm{~m}$. But when the pipeline length increases from $3 \mathrm{~m}$ to $5 \mathrm{~m}$, the $\dot{D}$ and $D_{40 \mathrm{y}}$ will not increase, since the two ends contribute very little 


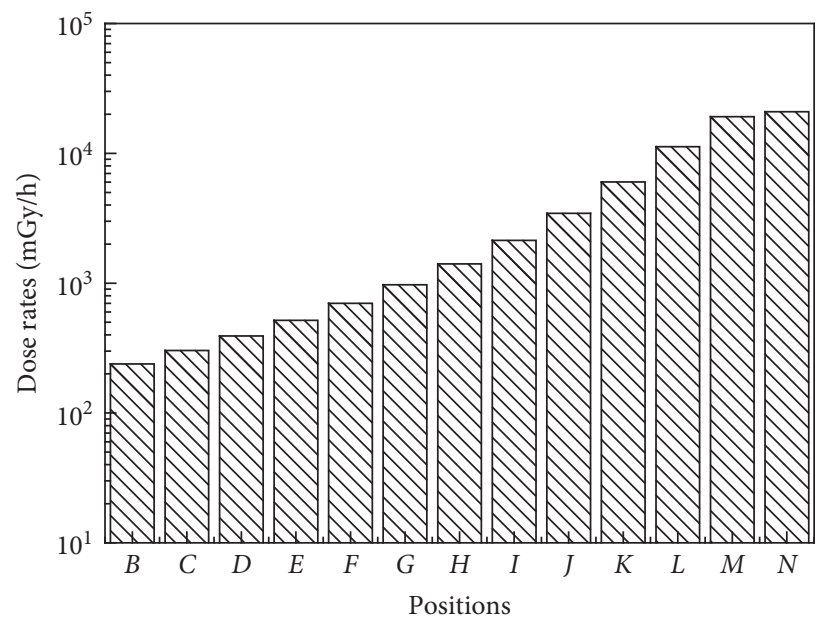

MIV Dose rates

FIgURE 3: The dose rates from one spent fuel element $(D p i=30 \mathrm{~cm}, 5 \mathrm{~m}$ pipeline, no shielding).

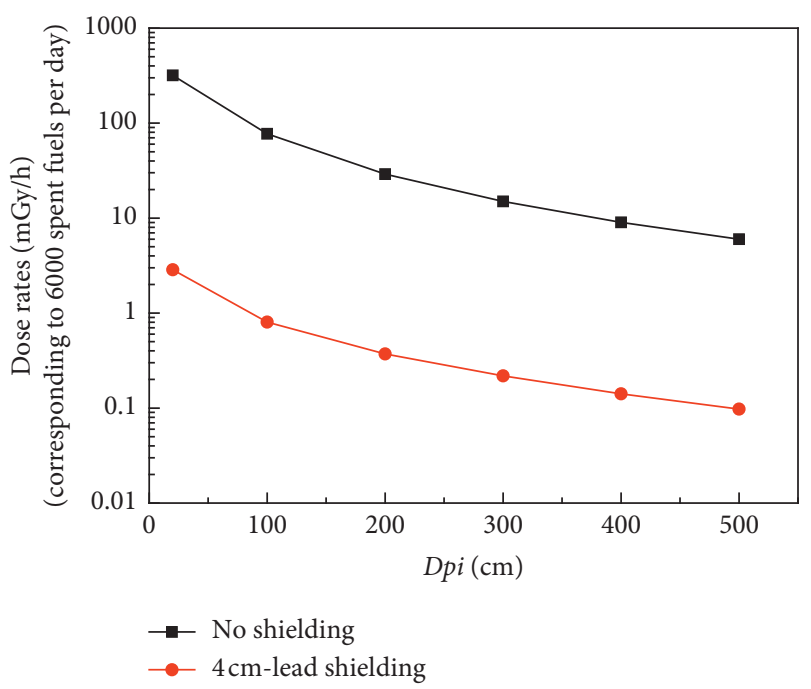

FIgURE 4: $\dot{\mathrm{D}}$ at different $\mathrm{Dpi}$ positions for a $5 \mathrm{~m}$ pipeline.

dose to the point of interest for a long pipeline. Compared with the dose limit of $3 \mathrm{mGy} / \mathrm{h}$, a $4 \mathrm{~cm}$ lead shielding should be suitable for pipelines of different lengths.

Also, compared with the radiation damage thresholds list in Table 1 , with a $4 \mathrm{~cm}$ lead shielding, the highest $D_{40 y}$ is $1000 \mathrm{~Gy}$, lower than the plastics losing tensile strength and natural rubber losing elasticity thresholds.

\subsection{For Pipelines That Transport Fuel Elements with Different} Burn-Up. For pipelines that transport fuel elements with different burn-up, the average burn-up fuel source term was adopted. Table 3 lists the calculated results of $\dot{D}$ and $D_{40 y}$ for pipelines of $1-5 \mathrm{~m}$ lengths at $D p i=30 \mathrm{~cm}$ 's position. Three scenarios were considered: with no shielding, with a $4.5 \mathrm{~cm}$ lead shielding, and with a $5 \mathrm{~cm}$ lead shielding.

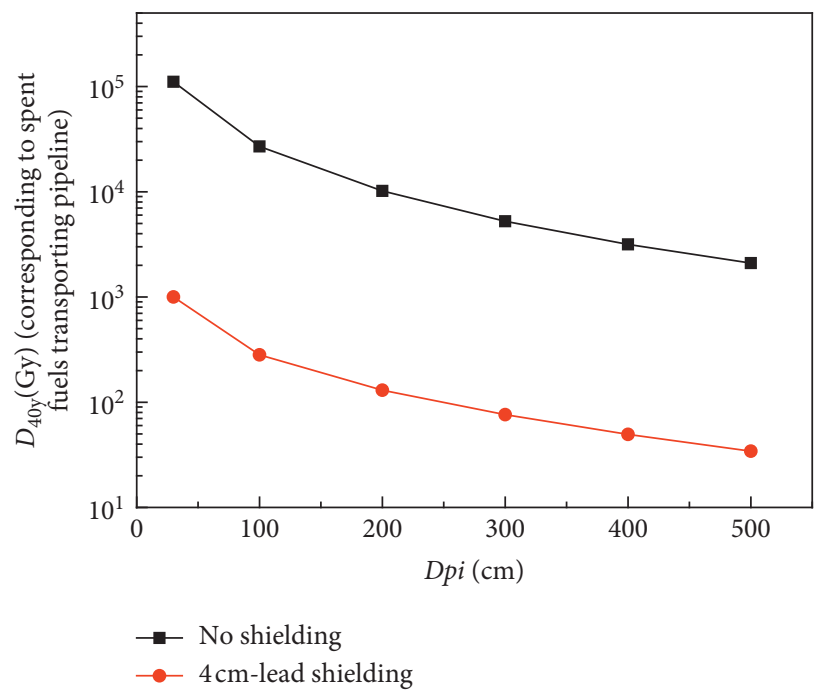

Figure 5: $D_{40 \mathrm{y}}$ at different $D p i$ positions for a $5 \mathrm{~m}$ pipeline.

From Table 3, it can be seen that, for with no shielding case, the $\dot{D}$ increases from $371 \mathrm{mGy} / \mathrm{h}$ to $518 \mathrm{mGy} / \mathrm{h}$ for $1-5 \mathrm{~m}$ pipelines. With a $4.5 \mathrm{~cm}$ lead shielding, the $\dot{D}$ can be reduced by 2 orders of magnitude, but still higher than the dose limit of $3 \mathrm{mGy} / \mathrm{h}$. With a $5 \mathrm{~cm}$ lead shielding, the $\dot{D}$ can be reduced to lower than $3 \mathrm{mGy} / \mathrm{h}$. Similar to the spent fuel transport case, the phenomenon happened that the $\dot{D}$ and $D_{40 y}$ did not increase when the pipeline length increased from $2 \mathrm{~m}$ to $5 \mathrm{~m}$ for with lead shielding case. This is also because the oblique lead shields at both ends of the long pipeline greatly attenuate the dose.

Also, compared with the radiation damage thresholds list in Table 1 , with a $5 \mathrm{~cm}$ lead shielding, the highest $D_{40 y}$ is $908 \mathrm{~Gy}$, lower than the plastics losing tensile strength and natural rubber losing elasticity thresholds. 
Table 2: $\dot{D}$ and $D_{40 y}$ at $D p i=30 \mathrm{~cm}$ for $1-5 \mathrm{~m}$ pipelines for the spent fuel source term.

\begin{tabular}{lcccc}
\hline \multirow{2}{*}{ Pipeline length $(\mathrm{m})$} & \multicolumn{2}{c}{$\dot{D}(\mathrm{mGy} / \mathrm{h})$} & \multicolumn{2}{c}{$D_{40 y}(\mathrm{~Gy})$} \\
& With no shielding & $4 \mathrm{~cm}$ lead shielding & With no shielding & $4 \mathrm{~cm}$ lead shielding \\
\hline 1 & 227 & 2.72 & $7.97 \times 10^{4}$ & 953 \\
2 & 286 & 2.85 & $1.00 \times 10^{5}$ & 999 \\
3 & 306 & 2.86 & $1.07 \times 10^{5}$ & 1000 \\
4 & 314 & 2.86 & $1.10 \times 10^{5}$ & 1000 \\
5 & 318 & 2.86 & $1.11 \times 10^{5}$ & 1000 \\
\hline
\end{tabular}

TABle 3: $\dot{D}$ and $D_{40 \text { y }}$ at $D p i=30 \mathrm{~cm}$ for $1-5 \mathrm{~m}$ pipelines for the average burn-up fuel source term.

\begin{tabular}{|c|c|c|c|c|c|c|}
\hline \multirow{2}{*}{ Pipeline lengths (m) } & \multicolumn{3}{|c|}{$\dot{D}(\mathrm{mGy} / \mathrm{h})$} & \multicolumn{3}{|c|}{$D_{40 \mathrm{y}}(\mathrm{Gy})$} \\
\hline & No shielding & $4.5 \mathrm{~cm}$ lead & $5 \mathrm{~cm}$ lead & No shielding & $4.5 \mathrm{~cm}$ lead & $5 \mathrm{~cm}$ lead \\
\hline 1 & 371 & 3.49 & 2.49 & $1.30 \times 10^{5}$ & 1220 & 871 \\
\hline 2 & 467 & 3.66 & 2.59 & $1.64 \times 10^{5}$ & 1280 & 907 \\
\hline 3 & 498 & 3.66 & 2.59 & $1.75 \times 10^{5}$ & 1280 & 908 \\
\hline 4 & 511 & 3.66 & 2.59 & $1.79 \times 10^{5}$ & 1280 & 908 \\
\hline 5 & 518 & 3.66 & 2.59 & $1.82 \times 10^{5}$ & 1280 & 908 \\
\hline
\end{tabular}

So, a $5 \mathrm{~cm}$ lead shielding should be added for pipelines that transport fuel elements with different burn-up.

\section{Conclusions}

In this work, the radiation protection design and dose evaluation were performed for the fuel transport pipelines for the HTR-PM reactor, using the shielding calculation software QAD-CGA program. Two types of fuel transport pipelines were considered, i.e., the spent fuel element transport pipelines and different burn-up fuel element transport pipelines. Correspondingly, two source terms were adopted: one is the spent fuel source term and the other is the average burn-up fuel source term. The moving process of a fuel element is discretized and dose calculations were performed to fuel elements at different positions. These doses were integrated with the moving time to obtain the total dose. For pipelines that transport the spent fuel, two scenarios were considered: with no shielding and with a $4 \mathrm{~cm}$ lead shielding. For pipelines that transport fuel elements with different burn-up, three scenarios were considered: with no shielding, with a $4.5 \mathrm{~cm}$ lead shielding, and with a $5 \mathrm{~cm}$ lead shielding. For each case, the point-by-point dose rate by one spent fuel element, the average hourly dose rate from 6000 elements per day, and the cumulative dose of 40 years from 6000 elements per day were calculated. Different Dpi and pipeline lengths were considered. To evaluate the shielding effect, the HTR-PM's orange radiation zone dose limit of $3 \mathrm{mGy} / \mathrm{h}$ and the radiation damage thresholds from NCRP report 51 were both adopted. The calculated results indicate that, for pipelines that transport the spent fuel and different burn-up fuel elements, a $4 \mathrm{~cm}$ and a $5 \mathrm{~cm}$ lead shielding should be added separately.

\section{Data Availability}

The data used to support the findings of this study are available from the corresponding author upon request.

\section{Conflicts of Interest}

The authors declare that they have no conflicts of interest.

\section{Acknowledgments}

This work was supported by the National Natural Science Foundations of China (grant no. 11875037) and the Foundation of Key Laboratory of Advanced Reactor Engineering and Safety, Ministry of Education (grant no. ARES2018-08).

\section{References}

[1] Z. Y. Zhang, Y. J. Dong, W. W. Qi et al., "Making dreams come true," Nuclear Engineering International, vol. 64, no. 755, pp. 16-18, 2019.

[2] Z. Y. Zhang, Y. J. Dong, F. Li et al., "The Shandong shidao bay 200 MWe high-temperature gas-cooled reactor pebble-bed module (HTR-PM) demonstration power plant: an engineering and technological innovation," Engineering, vol. 2, pp. 112-118, 2016.

[3] Z. Y. Zhang, Z. X. Wu, D. Z. Wang et al., "Current status and technical description of Chinese 2 x 250 MWth HTR-PM demonstration plant," Nuclear Engineering and Design, vol. 239, pp. 1212-1219, 2009.

[4] Z. Y. Zhang and Y. H. Sun, "Economic potential of modular reactor nuclear power plants based on the Chinese HTR-PM project," Nuclear Engineering and Design, vol. 237, pp. 2265-2274, 2007.

[5] Z. Y. Zhang and Y. L. Sun, "Current status of nuclear power and HTR development in China," Atw-International Journal for Nuclear Power, vol. 51, p. 784, 2006.

[6] S. Fang, H. Li, and W. Q. Li, "Radiation protection calculation and optimization for shielding design around the refueling pipelines of HTR-PM," in Proceedings of the 26th International Conference on Nuclear Engineering, London, UK, 2018.

[7] A. Leal and B. Gamboa, "Dose distribution calculation with MCNP code in a research irradiator," Radiation Physics and Chemistry, vol. 167, p. 5, 2020. 
[8] D. B. Pelowitz, MCNPX User's Manual. 2008. Version 2. 6. 0, Los Alamos Scientific Lab, New Mexico, USA, 2010.

[9] S. Shalbi, N. Sazali, and W. N. W. Salleh, "A simulation on desired neutron flux for the boron neutron capture therapy (BNCT) purpose by using Monte Carlo N-Particle (MCNPX)," IOP Conference Series: Materials Science and Engineering, vol. 736, p. 062022, 2020.

[10] A. Ferrari, P. R. Sala, A. Fasso et al., FLUKA: A Multi-Particle Transport Code, CERN European Organization for Nuclear Research, Geneva, Switzerland, 2008.

[11] S. Agostinelli et al., "Geant4-a simulation toolkit," Nuclear Instruments and Methods in Physics Research Section A, vol. 506, pp. 250-303, 2003.

[12] Z. M. Hu, Y. H. Zheng, T. S. Fan et al., "Experimental evaluation of the Geant4-calculated response functions of a Bonner sphere spectrometer on monoenergetic neutron sources," Nuclear Instruments \& Methods in Physics Research Section A-Accelerators Spectrometers Detectors and Associated Equipment, vol. 965, p. 6, 2020.

[13] Y. Harima, "An historical review and current status of buildup factor calculations and applications," Radiation Physics and Chemistry, vol. 41, pp. 631-672, 1993.

[14] J. K. Shultis and R. E. Faw, "Radiation shielding technology," Health Physics, vol. 88, no. 4, pp. 297-322, 2005.

[15] S. Fang, H. Li, J. Z. Cao et al., "Gamma dose rate estimation and operation management suggestions for decommissioning the reactor pressure vessel of HTR-PM," in Proceedings of the ASME 2013 15th International Conference on Environmental Remediation and Radioactive Waste Management, Brussels, Belgium, 2013.

[16] W. Li, X. Liu, L. Ming et al., "Multilayer shielding design for intermediate radioactive waste storage drums: a comparative study between FLUKA and QAD-CGA," Science and Technology of Nuclear Installations, vol. 2019, Article ID 8186798, 11 pages, 2019.

[17] W. Li, X. Liu, F. Sheng et al., "Monte Carlo simulation and experimental validation for radiation protection with multiple complex source terms and deep penetration for a radioactive liquid waste cementation facility," Science and Technology of Nuclear Installations, vol. 2020, Article ID 8819794, 13 pages, 2020.

[18] R. E. Malenfant, A Series Of Point-Kernel General Purpose Shielding Programs, Los Alamos Scientific Lab, New Mexico, USA, 1966.

[19] W. Y. Wang, L. G. Zhang, J. Z. Cao et al., "Optimization of the radiation shielding program QAD," Nuclear Engineering, vol. 4 , p. 8, 2016.

[20] M. Bell, ORIGEN-the ORNL Isotope Gened Depletion Code, Oak Ridge National Lab., Oak Ridge, TN, USA, 1973.

[21] U. Fischer and H. W. Wiese, Verbesserte Konsistente Berechnung des Nuklearen Inventars Abgebrannter DWRBrennstoffe auf der Basis von Zell-Abbrand-Verfahren mit KORIGEN, Institute for Neutron Physics and Reactor Technology Nuclear Research Center, Karlsruhe, Germany, 1983.

[22] W. Li, F. Sheng, and L. Hong, "Research on the induced radioactivity of HTR-PM's reactor pressure vessel: a comparative study between FLUKA, KORIGEN and QAD-CGA," Annals of Nuclear Energy, vol. 114, pp. 129-135, 2018.

[23] J. L. Muswema, "Source term derivation and radiological safety analysis for the TRICO II research reactor in kinshasa," Nuclear Engineering and Design, vol. 281, pp. 51-57, 2015.

[24] W. H. Yan, "Prototype studies on the nondestructive online burnup determination for the modular pebble bed reactors," Nuclear Engineering and Design, vol. 267, pp. 172-179, 2014.
[25] W. Li, F. Sheng, L. Hong et al., "Evaluation of the shielding effect of the spent fuel storage tank cover of HTR-PM: prediction calculation by QAD-CGA program," in Proceedings of the 27th International Conference on Nuclear Engineering, Glasgow, UK, 2019b. 